\title{
High-Power Laser Cutting of Steel Plates: Heat Affected Zone Analysis
}

\author{
Imed Miraoui, ${ }^{1,2}$ Mohamed Boujelbene, ${ }^{3}$ and Mouna Zaied ${ }^{2}$ \\ ${ }^{1}$ Department of Mechanical Engineering, College of Engineering, Aljouf University, Sakaka 2014, Saudi Arabia \\ ${ }^{2}$ College of Sciences, Research Unit MEER, University of Gafsa, 2100 Gafsa, Tunisia \\ ${ }^{3}$ Department of Industrial Engineering, College of Engineering, Hail University, Hail, Saudi Arabia
}

Correspondence should be addressed to Imed Miraoui; aimed_mir@yahoo.fr

Received 19 November 2015; Revised 7 February 2016; Accepted 11 February 2016

Academic Editor: Anna Richelli

Copyright (C) 2016 Imed Miraoui et al. This is an open access article distributed under the Creative Commons Attribution License, which permits unrestricted use, distribution, and reproduction in any medium, provided the original work is properly cited.

\begin{abstract}
The thermal effect of $\mathrm{CO}_{2}$ high-power laser cutting on cut surface of steel plates is investigated. The effect of the input laser cutting parameters on the melted zone depth (MZ), the heat affected zone depth (HAZ), and the microhardness beneath the cut surface is analyzed. A mathematical model is developed to relate the output process parameters to the input laser cutting parameters. Three input process parameters such as laser beam diameter, cutting speed, and laser power are investigated. Mathematical models for the melted zone and the heat affected zone depth are developed by using design of experiment approach (DOE). The results indicate that the input laser cutting parameters have major effect on melted zone, heat affected zone, and microhardness beneath cut surface. The MZ depth, the HAZ depth, and the microhardness beneath cut surface increase as laser power increases, but they decrease with increasing cutting speed. Laser beam diameter has a negligible effect on HAZ depth but it has a remarkable effect on MZ depth and HAZ microhardness. The melted zone depth and the heat affected zone depth can be reduced by increasing laser cutting speed and decreasing laser power and laser beam diameter.
\end{abstract}

\section{Introduction}

Laser cutting process is used extensively in industries to achieve complex shapes with close tolerances. Compared to conventional cutting, laser cutting has more advantages such as small heat affected zone, accurate cutting, noncontact processing, and short time of processing [1]. The manufacturers are interested in using the laser cutting to optimize both the quality and the productivity of the items made by this process. The productivity and the quality are essentially related to the selection of the suitable parameters of laser cutting such as laser power, laser beam diameter, and cutting speed [2-4]. During laser cutting process, we have a thermal interaction and a mechanical interaction between matter and the laser cutting parameters. The heat affected zone (HAZ) is the zone of the base material which has not melted but whose microstructure and mechanical properties were affected by the heat generated during laser cutting. The heat generated by the laser cutting process and after cooling causes this change in the region near the cut surface. The heat affected zone may lead to undesirable effects such as fatigue resistance, surface cracking, and distortion. So, it is interesting to select the appropriate laser cutting parameters in order to minimize the heat affected zone.

Several studies were performed to examine the effect of the input laser cutting parameters on the quality of the cut surface and the heat affected zone.

Eltawahni et al. [5] have investigated the effect of laser cutting parameters on the kerf width and the cut surface roughness of MDF composite material. They have shown that the upper and lower kerf widths decrease as cutting speed increases and they increase as laser power increases. An experimental investigation of laser cutting of polymeric materials was done by Choudhury and Shirley [6]. They have concluded that the heat affected zone depth is proportional to laser power and inversely proportional to compressed air pressure and cutting speed. Radovanovic and Dasic [7] have examined the influence of laser cutting parameters 
on the roughness of cut surface for mild steel. They have concluded that the cut surface roughness increases as the sheet thickness increases and decreases as the laser power increases. Miraoui et al. [8,9] have analyzed the surface roughness, microhardness, and microstructure of stainless steel sheet made by high-power laser cutting. They have indicated that the cutting of stainless steel sheets made by high-power laser had major effects on the microstructure and the roughness of the cut surface. They have showed that the laser cutting leads to the formation of cracks and periodic striations at the cut surface. Rajaram et al. [10] have investigated the $\mathrm{CO}_{2}$ laser cut quality of 4130 steel and they have shown that the kerf and HAZ widths were influenced significantly by laser power, while cutting speed has played a minor role. Kumar Dubey and Yadava [11] have optimized the laser beam cutting process using a hybrid Taguchi method and response surface method with multiperformance characteristics for thin sheet of high silicon-alloy steel. An experimental investigation of the laser cutting parameters for ceramic composite was done by Quintero et al. [12]. They have indicated the influence of cutting speed, frequency, and assist gas pressure on heat affected zone. Prasad et al. [13] have discussed the laser cutting of metallic coated sheet steels of $1 \mathrm{~mm}$ as thickness. Miraoui et al. [14] have analyzed the effect of laser beam diameter on the melted zone and microhardness beneath the cut surface. They have concluded that the width of the melted zone depends on the laser beam diameter. Li et al. [15] have used the experimental method of Taguchi to obtain the optimal laser cutting parameters. They have concluded that the quality of laser cutting of QFN packages depends mainly on laser frequency, cutting speed, and laser driving current. Huehnlein et al. [16] have used the design of experiment (DOE) approach to optimize the laser cutting of thin ceramic layers. Miraoui et al. [17] have studied the effect of laser beam diameter and laser power on cut surface roughness of steel plates. They have indicated that the influence of laser beam diameter on cut surface roughness is negligible and the increasing of laser power improves the surface roughness. Grum and Zuljan [18] have analyzed the heat for laser cutting of steel. They have shown that the cutting quality was influenced by the high temperature zone developed in the cutting front.

In this study, the heat affected zones of low carbon steel plates obtained by $\mathrm{CO}_{2}$ laser cutting were investigated. Laser power, cutting speed, and laser beam diameter were varied in order to analyze the effect of these input laser cutting parameters on heat affected zone depth and on microhardness beneath the cut surface. Design of experiment approach has been used in order to predict the relationship between the process parameters and heat affected zone depth.

\section{Experimental Methods}

The cutting operations were performed on a $\mathrm{CO}_{2}$ laser machine type AMADA AS $4000 \mathrm{E}$. The dimensional capacity of this machine is $3000 \times 1500 \mathrm{~mm}$ with an accuracy of cutting of $\pm 0.1 \mathrm{~mm}$. For experimentation, low carbon steel sheet with thickness of $8 \mathrm{~mm}$ was used. The dimensions of

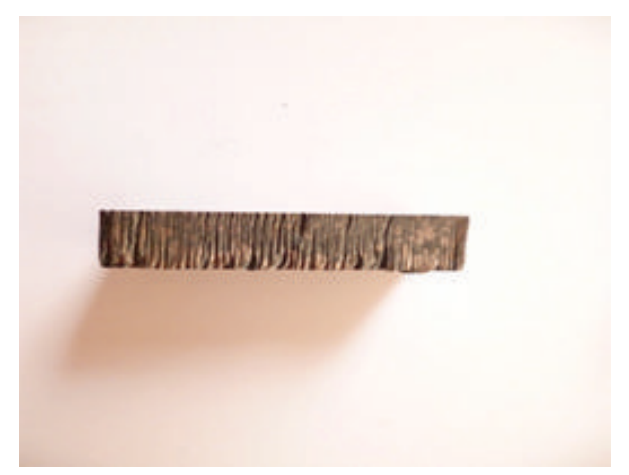

FIGURE 1: Low carbon steel plate carved by $\mathrm{CO}_{2}$ laser.

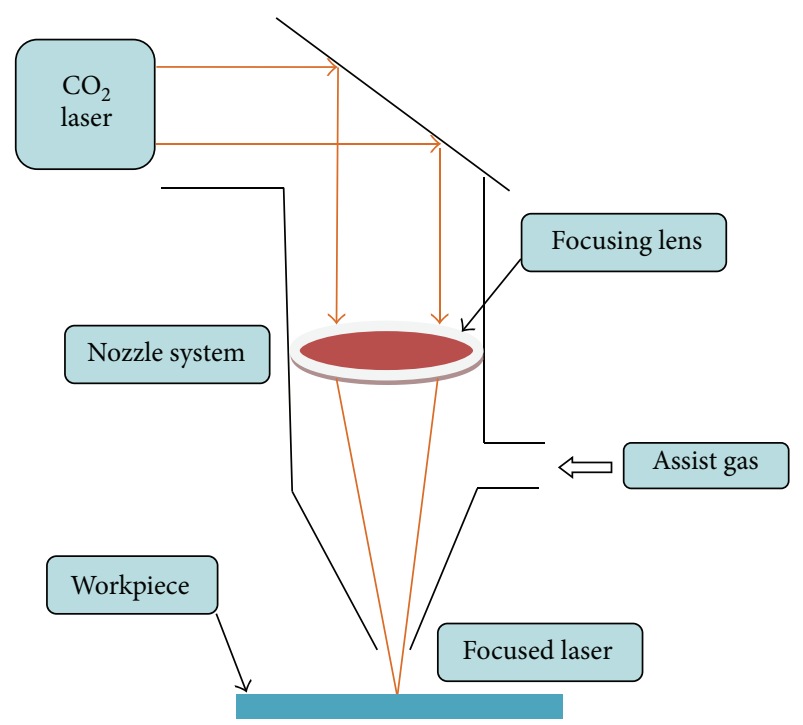

FIGURE 2: Experimental setup for laser cutting process.

TABLE 1: Chemical composition of S235 steel (wt\%).

\begin{tabular}{lccccc}
\hline $\mathrm{C}$ & $\mathrm{P}$ & $\mathrm{S}$ & $\mathrm{N}$ & $\mathrm{Mn}$ & $\mathrm{Si}$ \\
\hline $0.18 \%$ & $0.05 \%$ & $0.05 \%$ & $0.009 \%$ & $1.40 \%$ & $0.05 \%$ \\
\hline
\end{tabular}

the workpiece were $15 \mathrm{~mm}$ in width and $30 \mathrm{~mm}$ in length (see Figure 1). Chemical composition of this steel structure is given in Table 1, in which the Max\% levels of elements are indicated. The mechanical properties of this steel (S235) are presented in Table 2.

Cutting specimens were investigated experimentally using nominal output laser power $(P)$ ranged from 3 to $5 \mathrm{~kW}$, laser beam diameter $(D)$ ranged from 1 to $2 \mathrm{~mm}$, and cutting speed $(V)$ ranged $600-2200 \mathrm{~mm} / \mathrm{min}$. Figure 2 shows the experimental arrangement used in this study.

Vickers microhardness tester under a load of $50 \mathrm{~g}$, during $10 \mathrm{~s}$, was used to measure the microhardness beneath the cut surface of the specimens. The heat affected zone depths were measured by using optical microscopy. In order to examine the microstructure changes resulting from the laser cutting, we have used scanning electron microscopy, SEM. 

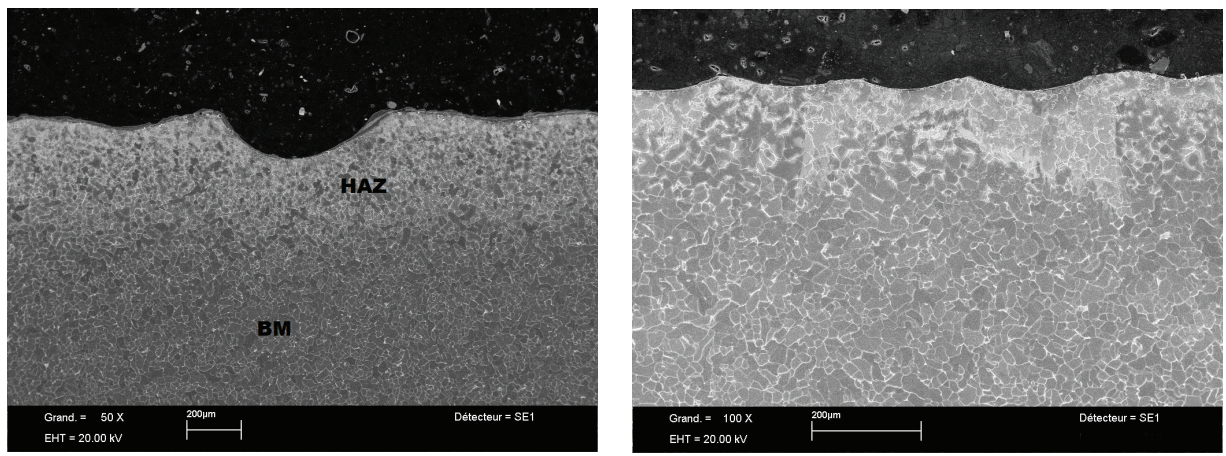

FIgURE 3: Microstructure of HAZ and base material (BM).

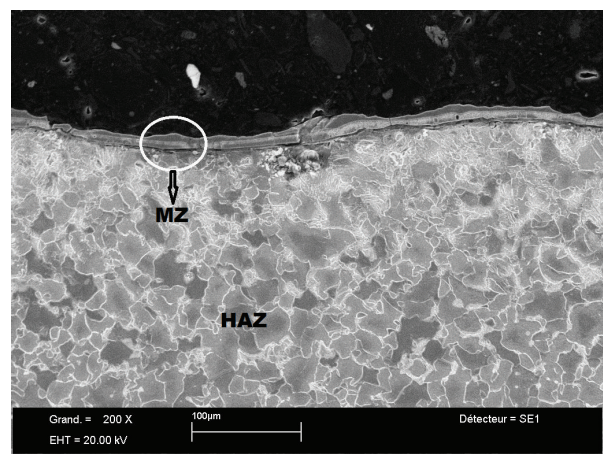

FIGURE 4: Microstructure of HAZ.

TABLE 2: Mechanical properties of S235 steel.

\begin{tabular}{lccc}
\hline $\begin{array}{l}\text { Elasticity } \\
\text { modulus }\end{array}$ & Poisson ratio & Density & $\begin{array}{c}\text { Tensile elastic } \\
\text { limit }\end{array}$ \\
\hline $205000 \mathrm{MPa}$ & 0.3 & $7800 \mathrm{~kg} / \mathrm{m}^{3}$ & $235 \mathrm{MPa}$ \\
\hline
\end{tabular}

\section{Results and Discussion}

3.1. Microstructure Analysis. The heat generated by the laser cutting process and after cooling has affected the microstructure of the region near the cut surface (HAZ). In the base material zone (BM), the material has not undergone any structural transformation (Figure 3 ). The result of microscopic analysis revealed the presence of a layered structure on the workpiece structure. Figure 4 shows the presence of a white layer called melted zone (MZ): zone of interaction beam-metal.

Full view and magnified image of cut surface microstructure is shown in Figure 5. It can be seen that laser cutting leads to the formation of cracks at the cut surface. Laser cutting had major effect on cut surface quality.

\subsection{HAZ Depth Analysis}

3.2.1. Experimental Study. The HAZ depth (zone beneath the cut surface) is one of the main performances of laser machining. The dimension of the heat affected zone (HAZ) was analyzed using optical microscope. HAZ is the area of
TABLE 3: Input laser cutting parameters and their levels.

\begin{tabular}{lcccc}
\hline Symbol & $\begin{array}{c}\text { Input } \\
\text { parameters }\end{array}$ & Unit & Level 1 & Level 2 \\
\hline$P$ & Laser power & $\mathrm{W}$ & 3000 & 5000 \\
$V$ & Cutting speed & $\mathrm{mm} / \mathrm{min}$ & 600 & 2200 \\
$D$ & $\begin{array}{c}\text { Laser beam } \\
\text { diameter }\end{array}$ & $\mathrm{mm}$ & 1 & 2 \\
\hline
\end{tabular}

the work material which was not melted during cutting but its microstructure was affected by the intense heat during laser cutting. While in the base material zone, the material has not undergone any structural transformation (see Figures 3 and 6). The interface between HAZ and base material (BM) is the limit between the affected and unaffected microstructure. To study the influence of the input laser cutting parameters (laser power, laser beam diameter, and cutting speed) on the HAZ depth, seven HAZ values of each specimen were measured using optic microscope and an average was calculated for each specimen (see Figure 6).

Figure 7 presents the effect of laser power and cutting speed on HAZ depth. These results indicate that laser power and cutting speed had major effect on heat affected zone. HAZ depth increases as laser power increases and it decreases as cutting speed increases. The variations of HAZ depth depending on laser beam diameter and laser power are presented in the curves of Figure 8. It was shown that laser beam diameter has a negligible effect on HAZ depth.

3.2.2. Modelling. The statistical processing of the experimental results enabled development of model equations to determine the HAZ depth according to the cutting parameters (laser power, laser beam diameter, and cutting speed). The DOE approach (Taguchi method) has been used to develop the model equation. The input process parameters and their levels used in the designed experiment are given in Table 3. The measured values of HAZ corresponding to each experimental condition are listed in Table 4.

Analysis of variance (ANOVA) has been carried out to determine the significant model terms. This method has a gap that gives estimation value with an error 5\%. Analysis of variance indicates that, on a significance level of 5\%, laser 

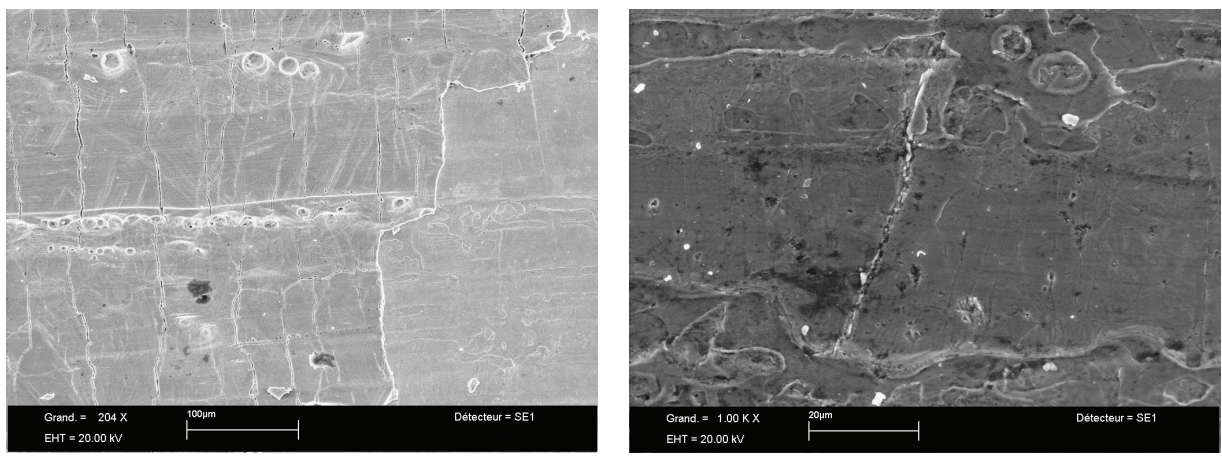

FIGURE 5: Full view and magnified images of cut surface microstructure.

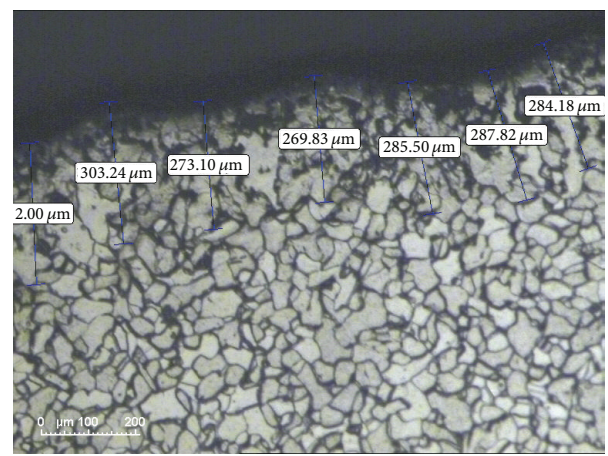

Figure 6: Measuring of HAZ depth.

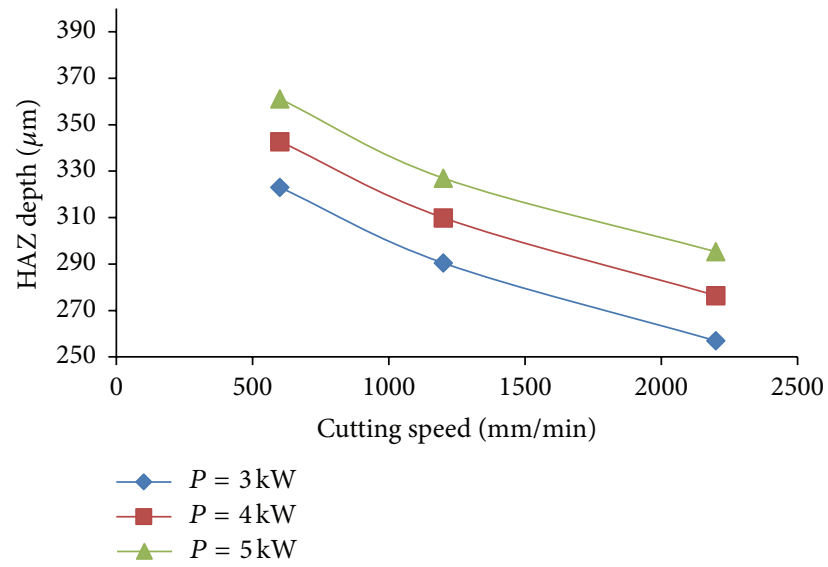

FIGURE 7: Effect of laser power and cutting speed on HAZ depth $(D=1 \mathrm{~mm})$.

power, cutting speed, and laser beam diameter are the most significant model terms, but their interaction does not have a significant effect on HAZ. It was observed that the laser power and the cutting speed are the most significant and the laser beam diameter is the least significant cutting parameters affecting the HAZ.

From the experimental data of HAZ depth, we have developed the following model equation:

$$
\mathrm{HAZ}=100.48 P^{0.259} V^{-0.146} D^{0.04} .
$$

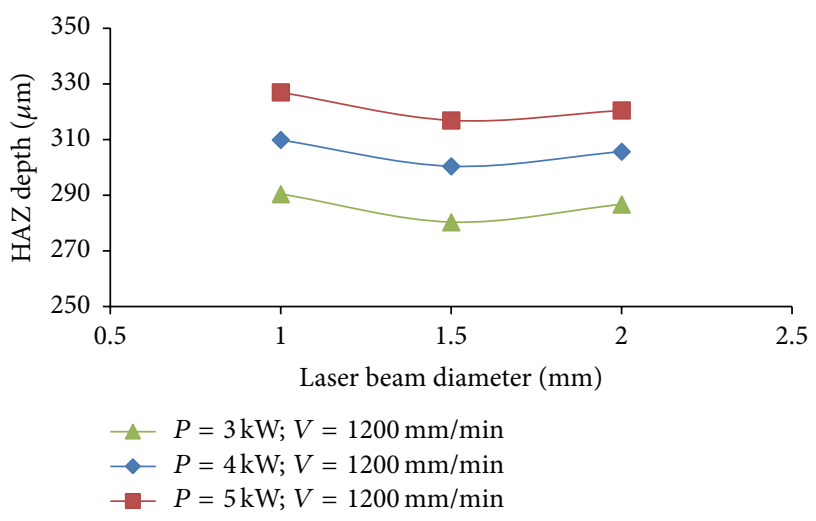

FiguRE 8: Effect of laser beam diameter on HAZ depth.

TABlE 4: Design matrix and experimentally measured response (HAZ).

\begin{tabular}{lcccc}
\hline Exp. number & $P(\mathrm{~W})$ & $V(\mathrm{~mm} / \mathrm{min})$ & $D(\mathrm{~mm})$ & $\mathrm{HAZ}(\mu \mathrm{m})$ \\
\hline 1 & 3000 & 600 & 1 & 323 \\
2 & 5000 & 600 & 1 & 360 \\
3 & 3000 & 2200 & 1 & 257 \\
4 & 5000 & 2200 & 1 & 295 \\
5 & 3000 & 600 & 2 & 325 \\
6 & 5000 & 600 & 2 & 361 \\
7 & 3000 & 2200 & 2 & 266 \\
8 & 5000 & 2200 & 2 & 317 \\
\hline
\end{tabular}

This equation shows that HAZ depth decreases with cutting speed and increases with laser power. The effect of laser power is more important than the effect of cutting speed on HAZ depth. It is clear that laser beam diameter has a negligible effect on HAZ depth. Laser power is the most important parameter affecting the HAZ. The increase in laser power generates the increase of the cut surface temperature which causes the increase of the heat affected zone. During the cooling period, it will have a change of phase in the solid state which is reflected in the increase of the heat affected zone depth. When the cutting speed is rapid, the propagation of heat in the sample is done in a shorter period of time which allows minimizing the cut surface damage and therefore 
TABLE 5: Confirmation experiments-HAZ.

\begin{tabular}{lccccc}
\hline$P(\mathrm{~W})$ & $V(\mathrm{~mm} / \mathrm{min})$ & $D(\mathrm{~mm})$ & Experimental HAZ & Modelled HAZ & Error\% \\
\hline 4000 & 600 & 1 & 342.73 & 338.37 & 291.83 \\
3000 & 1200 & 2 & 286.76 & -1.76 \\
5000 & 1200 & 1.5 & 316.98 & 329.30 & -3.88 \\
\hline
\end{tabular}

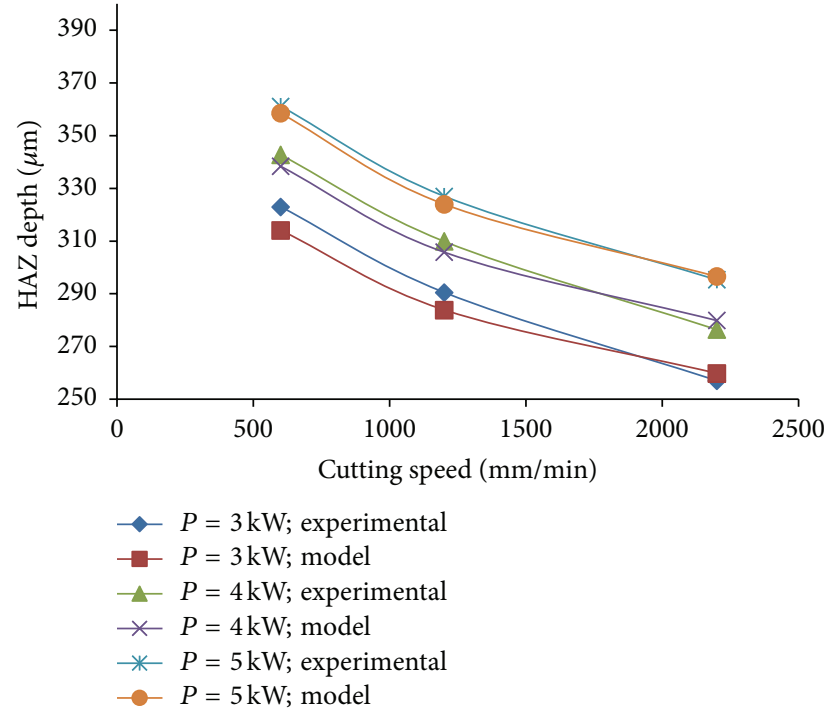

FIgURE 9: Comparison between experimental and modelled HAZ $\operatorname{depth}(D=1 \mathrm{~mm})$.

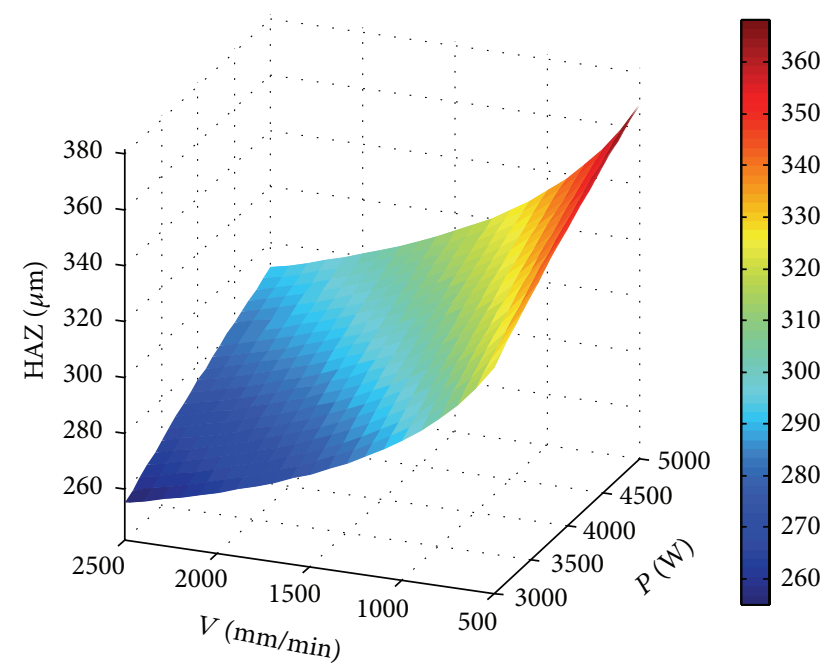

FIgURE 10: Response surface plot of HAZ depth with laser cutting speed and laser power $(D=1 \mathrm{~mm})$.

has a thermally finer affected zone. All these results are in good agreement with the experimental study, as shown in Figure 9. The combined effects of laser cutting speed and laser power on HAZ depth are shown in Figure 10, where laser beam diameter $(D)$ is kept at $1 \mathrm{~mm}$. Figure 11 presents the effects of laser power and laser beam diameter on HAZ

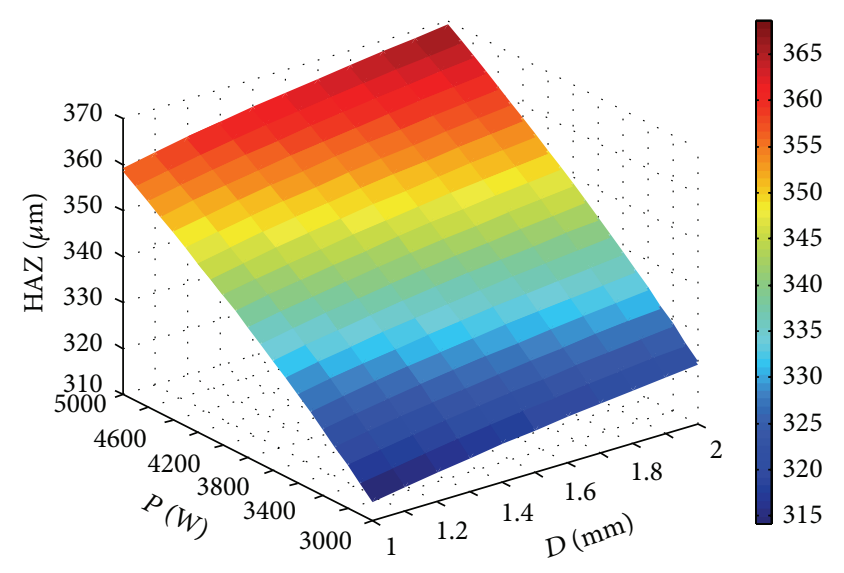

FIGURE 11: Response surface plot of HAZ depth with laser power and laser beam diameter $(V=600 \mathrm{~mm} / \mathrm{min})$.

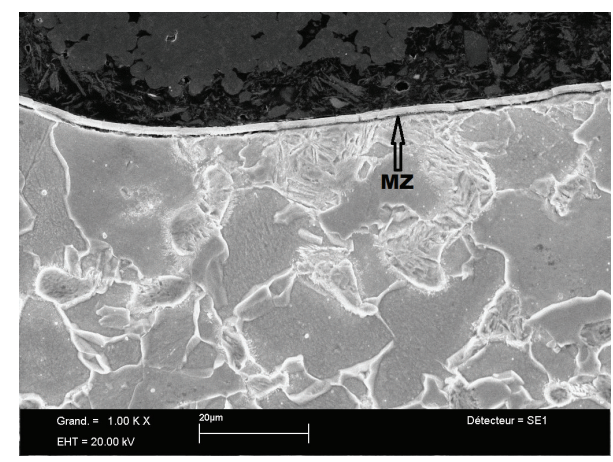

FIgURE 12: Measuring of MZ depth.

depth by keeping the laser cutting speed $(V)$ as constant at $600 \mathrm{~mm} / \mathrm{min}$.

To confirm the adequacy of the developed models, three confirmation experiments were performed using new test conditions. The values of HAZ of the confirmation experiments which were determined using the developed model show good agreement with the experimental values (see Table 5).

3.3. Analysis of MZ Depth. To study the influence of the input laser cutting parameters (laser power, laser beam diameter, and cutting speed) on the MZ depth (the zone of interaction beam-metal), we have measured the average MZ depth from several measurements performed at the surface perpendicular to the cut surface (see Figure 12). A mathematical model for the melted zone depth is developed by using design of experiment approach (DOE). Taguchi 
TABLE 6: Design matrix and experimentally measured response (MZ).

\begin{tabular}{lcccc}
\hline Exp. number & $P(\mathrm{~W})$ & $V(\mathrm{~mm} / \mathrm{min})$ & $D(\mathrm{~mm})$ & $\mathrm{MZ}(\mu \mathrm{m})$ \\
\hline 1 & 3000 & 600 & 1 & 1.2 \\
2 & 5000 & 600 & 1 & 2 \\
3 & 3000 & 2200 & 1 & 1 \\
4 & 5000 & 2200 & 1 & 1.75 \\
5 & 3000 & 600 & 2 & 2 \\
6 & 5000 & 600 & 2 & 3.20 \\
7 & 3000 & 2200 & 2 & 1.50 \\
8 & 5000 & 2200 & 2 & 2.50 \\
\hline
\end{tabular}

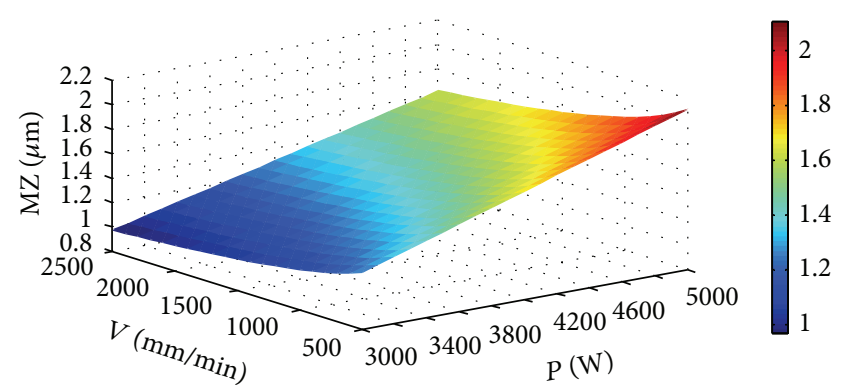

Figure 13: Response surface plot of MZ depth with laser cutting speed and laser power $(D=1 \mathrm{~mm})$.

method was used to determine the mathematical relationship between the response (MZ depth) and the input laser cutting machining (laser power, laser beam diameter, and cutting speed). The input process parameters and their levels used in the designed experiment are given in Table 3 . The measured values of $\mathrm{MZ}$ corresponding to each experimental condition are listed in Table 6. Analysis of variance (ANOVA) indicates that, on a significance level of $5 \%$, laser power, cutting speed, and laser beam diameter are the most significant model terms, but their interaction does not have a significant effect on MZ. It was observed that laser power and laser beam diameter are the most significant and the cutting speed is the least significant cutting parameters affecting the MZ.

From the experimental data of MZ depth, we have developed the following model equation:

$$
\mathrm{MZ}=0.00113 P^{1.0039} V^{-0.164} D^{0.6281} .
$$

It is clear that MZ depth decreases with cutting speed and increases with laser power. It can be seen that MZ depth increases with laser beam diameter, contrary to HAZ depth in which the diameter has a negligible effect. Laser power is the most important parameter affecting the MZ. The increase in laser power generates the increase of the cut surface temperature which causes the increase of the melted zone. If the cutting speed is rapid, the propagation of heat in the sample is done in a shorter period of time which allows minimizing the cut surface damage and therefore has a thermally finer MZ. The combined effects of laser cutting speed and laser power on MZ depth are shown in Figure 13, where laser beam diameter $(D)$ is kept at $1 \mathrm{~mm}$. Figure 14

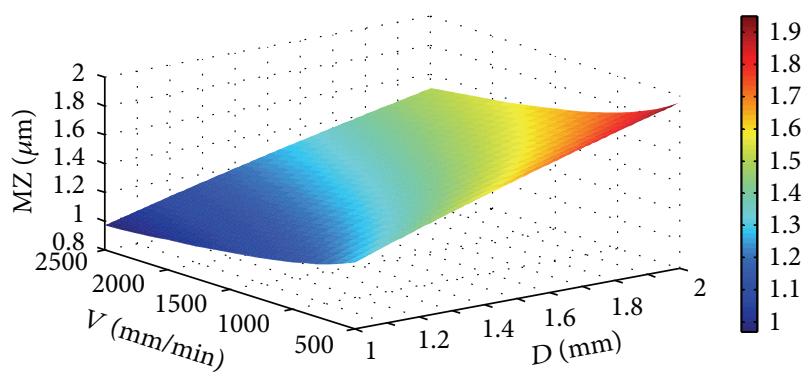

FIgURE 14: Response surface plot of MZ depth with laser cutting speed and laser beam diameter $(P=3000 \mathrm{~W})$.

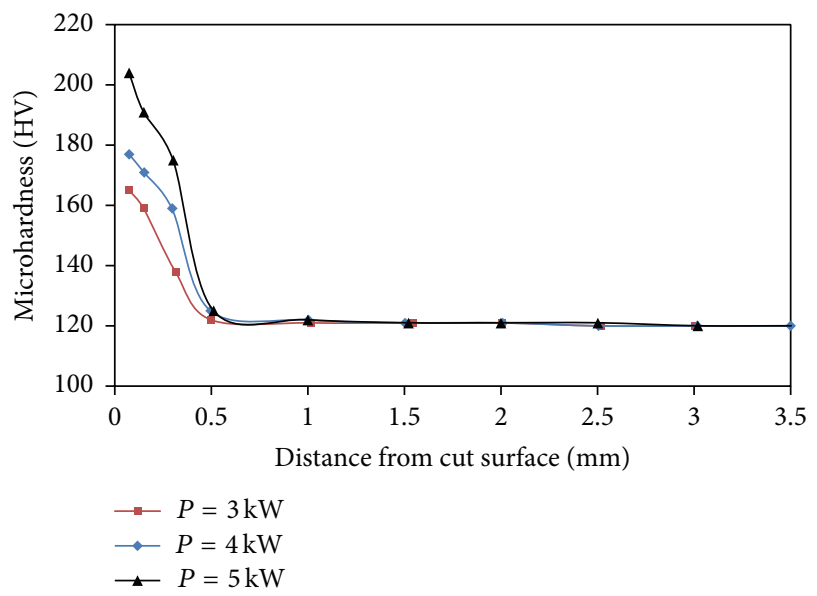

FIGURE 15: Effect of laser power on HAZ microhardness.

presents the effects of laser cutting speed and laser beam diameter on MZ depth by keeping the laser power $(P)$ as constant at $3000 \mathrm{~W}$.

To confirm the adequacy of the developed models, three confirmation experiments were carried out using new test conditions. The input laser cutting parameters, the experimental values, the modelled values, and the percentages of error are given in Table 7 . These results indicate that all the values of the percentage of the error are acceptable.

3.4. Analysis of HAZ Microhardness. This section discusses the effects of the input laser cutting parameters (laser power, laser beam diameter, and cutting speed) on the HAZ microhardness. The microhardness profile across machined surface depths produced at different laser power (cutting speed and laser beam diameter are constant) is shown in Figure 13. It was shown that the maximum microhardness is observed near the cut surface and gradually decreases until it reaches the microhardness of the base material $(120 \mathrm{HV}$ : the ordinary microhardness of low carbon steel S235 used in this work). Laser cutting has a thermal effect on the original structure due to the high temperature reached at the cut edge followed by a high rapid cooling. This results in a hardening zone at the cut edge (HAZ). As shown in Figure 15, the microhardness in the HAZ increases as laser power increases. 
TABLE 7: Confirmation experiments-MZ.

\begin{tabular}{lccccc}
\hline$P(\mathrm{~W})$ & $V(\mathrm{~mm} / \mathrm{min})$ & $D(\mathrm{~mm})$ & Experimental MZ & Modelled MZ & Error\% \\
\hline 5000 & 600 & 1.5 & 2.75 & -0.36 \\
4000 & 2200 & 1 & 1.40 & 1.36 & 2.9 \\
3000 & 2200 & 2 & 1.50 & 1.57 & -4.67 \\
\hline
\end{tabular}

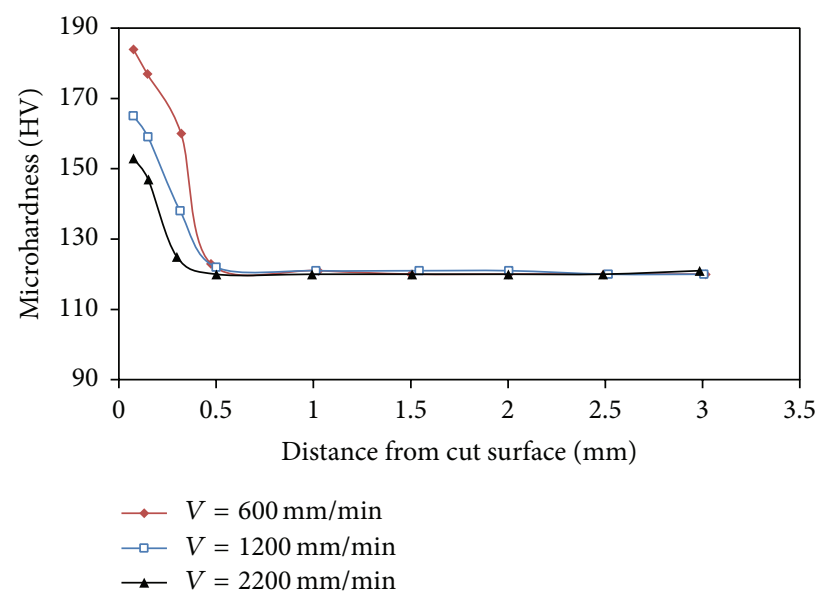

Figure 16: Effect of cutting speed on HAZ microhardness.

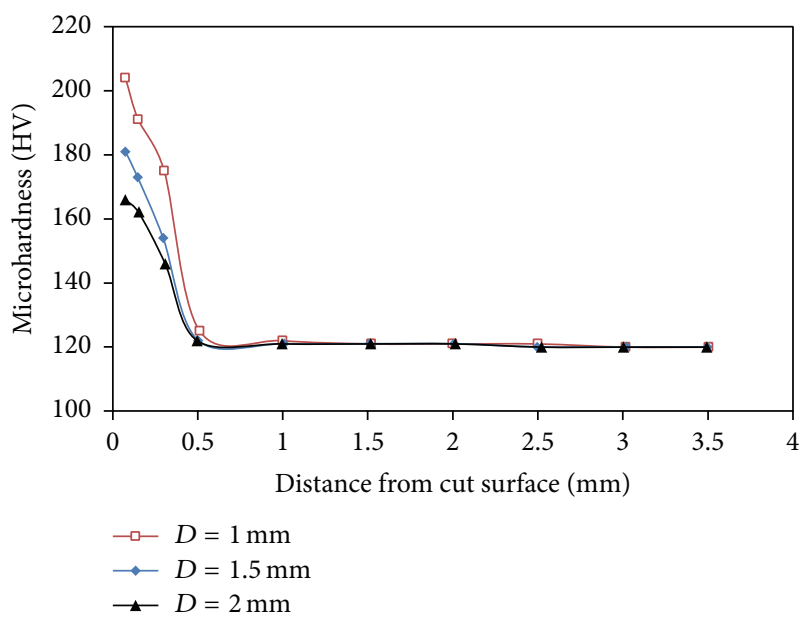

FIGURE 17: Effect of laser beam diameter on HAZ microhardness.

Figure 16 presents the effect of cutting speed on HAZ microhardness. It is clear that the microhardness in the HAZ decreases as cutting speed increases. The effect of laser beam diameter on HAZ microhardness is shown in Figure 17. These results indicate that laser beam diameter has an effect on HAZ microhardness. It decreases as laser beam diameter increases.

\section{Conclusions}

High-power $\mathrm{CO}_{2}$ laser cutting of low carbon steel plates is examined and the effects of the input process parameters such as laser power, laser beam diameter, and cutting speed on heat affected zone and melted zone have been investigated. The scanning electron microscopy and the optical microscope are used to analyze the microstructure and the HAZ depth. The microhardness beneath the cut surface was measured by using Vickers microhardness. Design of experiment approach has been used to predict the relationship between the input process parameters and the response (heat affected zone and melted zone). From the present work, the following conclusions can be drawn. The depth of MZ, the depth of HAZ, and the microhardness of HAZ depend on the input process parameters. The laser power and the cutting speed are the most significant and the laser beam diameter is the least significant cutting parameters affecting the HAZ. However, the laser power and the laser beam diameter are the most significant and the cutting speed is the least significant cutting parameters affecting the MZ. The dimension of HAZ increases as laser power increases, and it decreases as cutting speed increases. The MZ depth decreases with cutting speed and increases with laser power. Results show that MZ depth increases with laser beam diameter, contrary to HAZ depth in which the diameter has a negligible effect. Laser power is the most important parameter affecting the MZ. The microhardness in the HAZ increases as laser power increases, and it decreases as cutting speed and laser beam diameter increase. The undesirable thermal effect of laser cutting of low carbon steel plates can be reduced by increasing laser cutting speed and decreasing laser power and laser beam diameter.

\section{Conflict of Interests}

The authors declare that there is no conflict of interests regarding the publication of this paper.

\section{Acknowledgment}

The authors acknowledge the financial support from Aljouf University, KSA, under Grant no. 35/294.

\section{References}

[1] B. S. Yilbas, S. Khan, K. Raza et al., "Laser cutting of 7050 $\mathrm{Al}$ alloy reinforced with $\mathrm{Al}_{2} \mathrm{O}_{3}$ and $\mathrm{B}_{4} \mathrm{C}$ composites," The International Journal of Advanced Manufacturing Technology, vol. 50, no. 1-4, pp. 185-193, 2010.

[2] N. Jebbari, M. M. Jebari, F. Saadallah, A. Tarrats, R. Bennaceur, and J. P. Longuemard, "Themal affected zone obtained in machining steel XC42 by high-power $\mathrm{CO}_{2}$ laser," Optics and Laser Technology, vol. 40, no. 6, pp. 864-873, 2008.

[3] R. Ragendram and M. B. Pate, "The effect of laser beam velocity on cut quality and surface temperature," American Society of Mechanical Engineers, Heat Transfer Division, vol. 104, pp. 121127, 1998. 
[4] I. Decker, J. Ruge, and U. Atzert, "Physical models and technological aspects of laser gas cutting," in Proceedings of the Industrial Applications of High Power Lasers, vol. 4 of Proceeding of SPIE, pp. 81-88, Linz, Austria, March 1984.

[5] H. A. Eltawahni, A. G. Olabi, and K. Y. Benyounis, "Investigating the $\mathrm{CO}_{2}$ laser cutting parameters of MDF wood composite material," Optics and Laser Technology, vol. 43, no. 3, pp. 648659, 2011.

[6] I. A. Choudhury and S. Shirley, "Laser cutting of polymeric materials: an experimental investigation," Optics and Laser Technology, vol. 42, no. 3, pp. 503-508, 2010.

[7] M. Radovanovic and P. Dasic, "Research on surface roughness by laser cut," The Annals of University Dunarea de Jos of Galati Fasicule VIII, Tribology, vol. 12, pp. 84-88, 2006.

[8] I. Miraoui, E. Elimi, M. Boujelbene, and E. Bayraktar, "Analysis of roughness and microstructure for high-power laser cutting of stainless steel," Advanced Science Letters, vol. 19, no. 2, pp. 483486, 2013.

[9] I. Miraoui, E. Bayraktar, and E. Bayraktar, "Effects of laser cutting main parameters on microhardness and microstructure changes of stainless steel," Advanced Materials Research, vol. 664, pp. 811-816, 2013.

[10] N. Rajaram, J. Sheikh-Ahmad, and S. H. Cheraghi, " $\mathrm{CO}_{2}$ laser cut quality of 4130 steel," International Journal of Machine Tools and Manufacture, vol. 43, no. 4, pp. 351-358, 2003.

[11] A. Kumar Dubey and V. Yadava, "Multi-objective optimisation of laser beam cutting process," Optics \& Laser Technology, vol. 40, no. 3, pp. 562-570, 2008.

[12] F. Quintero, J. Pou, F. Lusquiños, M. Boutinguiza, R. Soto, and M. Pérez-Amor, "Quantitative evaluation of the quality of the cuts performed on mullite-alumina by Nd:YAG laser," Optics and Lasers in Engineering, vol. 42, no. 3, pp. 327-340, 2004.

[13] G. V. S. Prasad, E. Siores, and W. C. K. Wong, "Laser cutting of metallic coated sheet steels," Journal of Materials Processing Technology, vol. 74, no. 1-3, pp. 234-242, 1998.

[14] I. Miraoui, M. Zaied, and M. Boujelbene, "Effect of laser beam diameter on cut edge of steel plates obtained by laser machining," Applied Mechanics and Materials, vol. 467, pp. 227232, 2014

[15] C.-H. Li, M.-J. Tsai, and C.-D. Yang, "Study of optimal laser parameters for cutting QFN packages by Taguchi's matrix method," Optics and Laser Technology, vol. 39, no. 4, pp. 786795, 2007.

[16] K. Huehnlein, K. Tschirpke, and R. Hellmann, "Optimization of laser cutting processes using design of experiments," Physics Procedia, vol. 5, pp. 243-252, 2010.

[17] I. Miraoui, M. Boujelbene, and E. Bayraktar, "Analysis of roughness and heat affected zone of steel plates obtained by laser cutting," Advanced Materials Research, vol. 974, pp. 169$173,2014$.

[18] J. Grum and D. Zuljan, "Analysis of heat effects in laser cutting of steels," Journal of Materials Engineering and Performance, vol. 5, no. 4, pp. 526-537, 1996. 

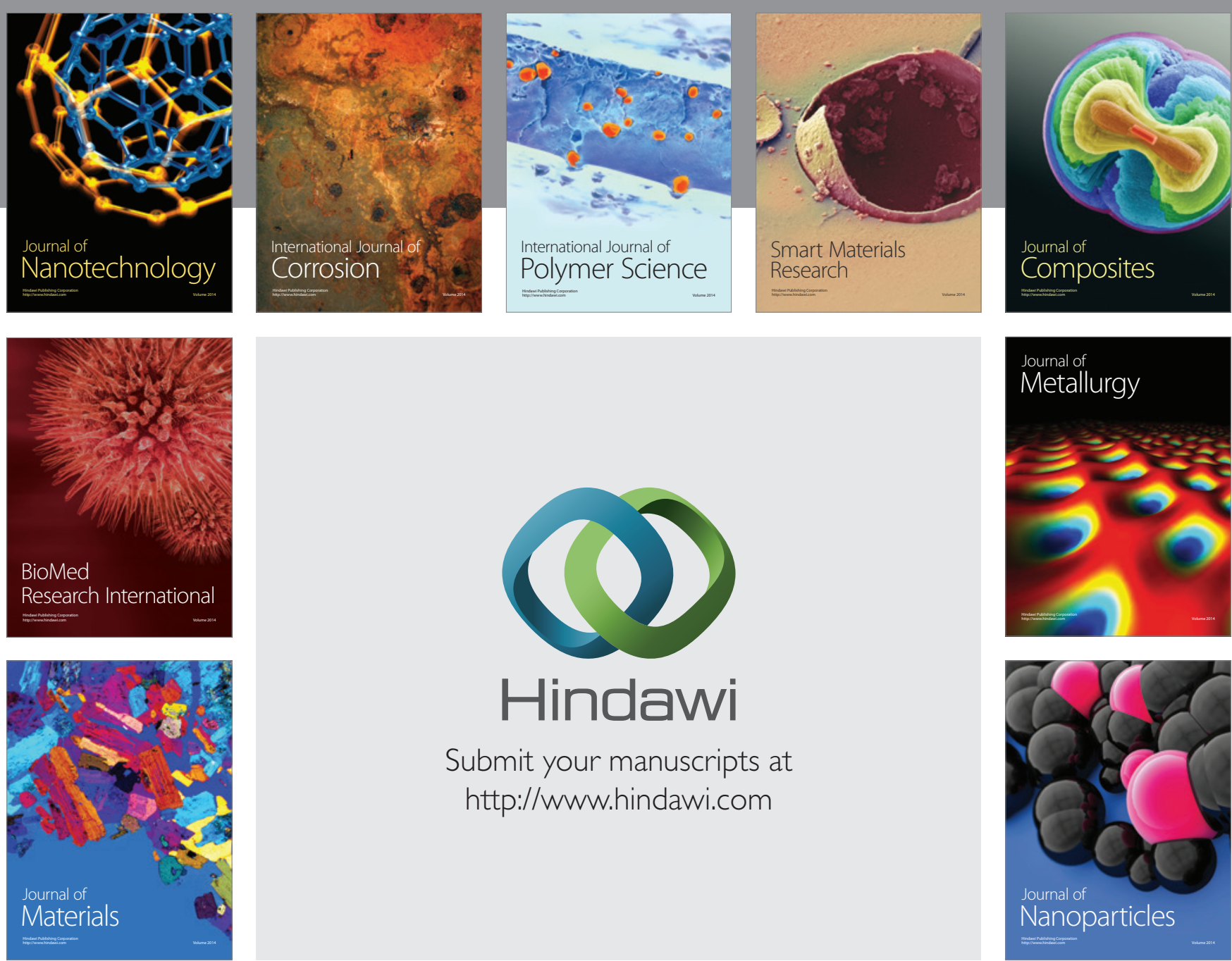

\section{Hindawi}

Submit your manuscripts at

http://www.hindawi.com

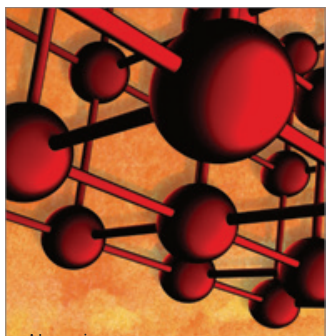

Materials Science and Engineering
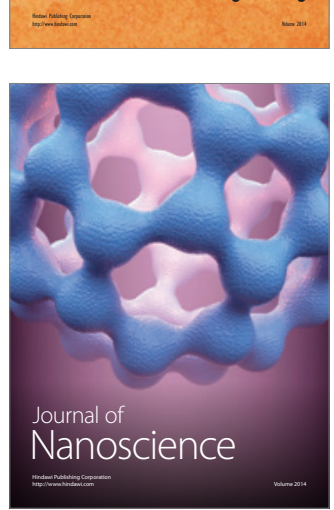
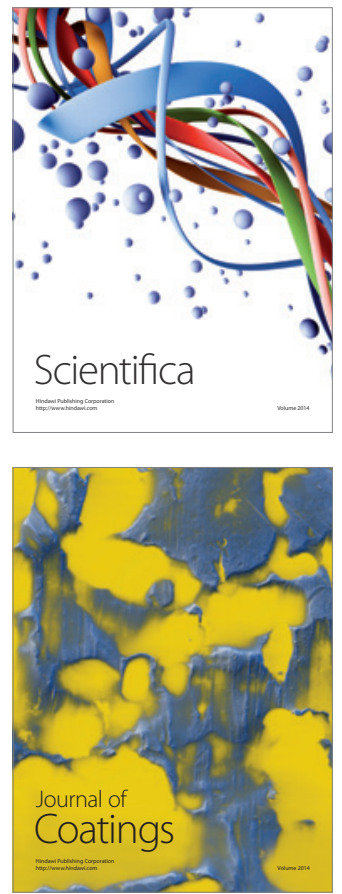
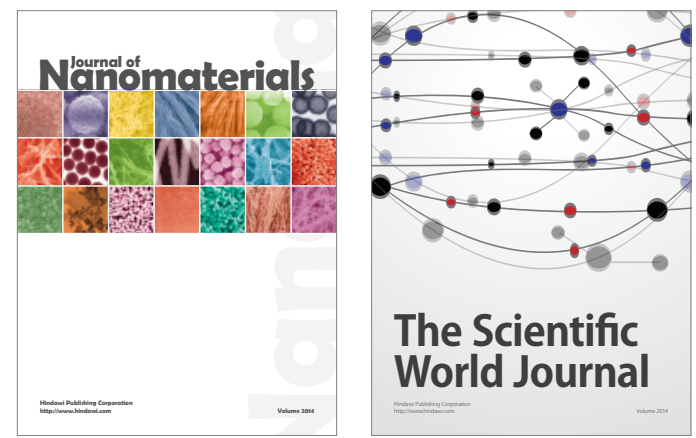

The Scientific World Journal
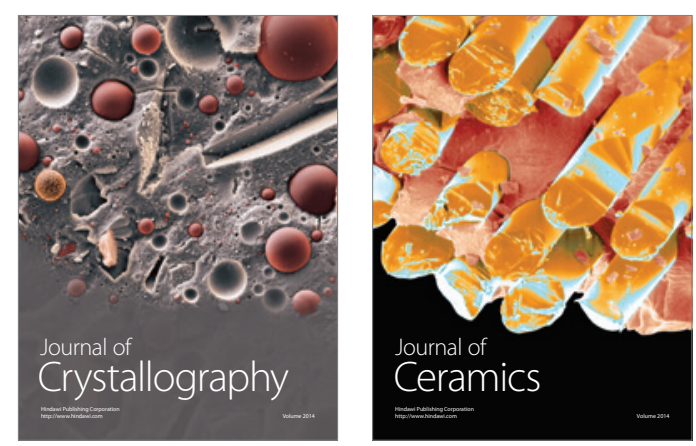
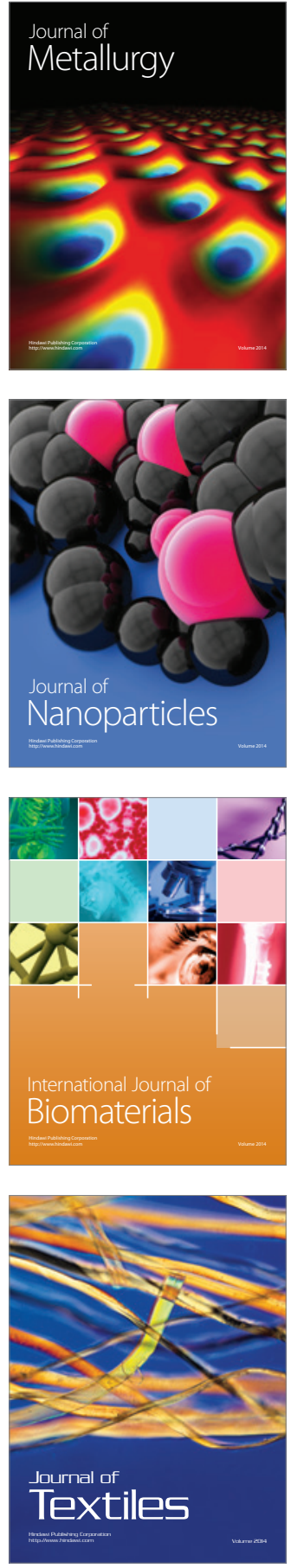